\title{
THE EFFECT OF SODIUM ALGINATE CONCENTRATION ON THE RHEOLOGICAL PARAMETERS OF SPINNING SOLUTIONS
}

\author{
Magdalena Brzezińska , Grzegorz Szparaga \\ Technical University of Lodz, Department of Material and Commodity Sciences and Textile Metrology, Zeromskiego 116, 90-924 Lodz, Poland \\ Email: grzegorz.szparaga@gmail.com
}

\begin{abstract}
:
The aim of the study was to determine the rheological properties of solutions of two types of sodium alginate in water. Rheological studies were carried out to determine the rheological properties of the spinning solutions. Polymer solutions of different concentrations were obtained. Based on the preliminary research of the concentrations of solutions, the proper $n$ and $k$ parameters were selected in order to obtain fibre by wet spinning from solution method. For selected concentrations of polymer solutions, the calcium alginate fibres were obtained.
\end{abstract}

\section{Keywords:}

Biodegradable polymer, alginate fibres, rheological parameters

\section{Introduction}

The process of formation of alginate fibres was first described in 1944 [1]. For years, these fibres were mostly produced for textile applications. While today such uses are negligible, new application opportunities are being sought for alginates and alginate fibres; these include tissue engineering, drug carriers, pharmaceuticals, dietary supplements, cosmetics, and wound dressings [2-14]. Alginates are obtained from algae in multistep processing, while fibres are produced from alginates by wet spinning from solution. Alginates are natural polysaccharides with a linear macromolecular structure, composed of blocks of (1-4)-linked $\beta$-D-mannuronat and $\alpha$-L-guluronate residues $[15,16]$. In wet spinning of alginate fibres, aqueous solutions of sodium alginate are used as spinning solutions. The concentration of the solutions must be such that apparent dynamic viscosity is in the range of 30-60 Pas, allowing for stable fibre formation. In the case of wet spinning from solution, the rheological properties of the spinning solutions influence its flow rate distribution as it flows through spinneret channels (the so-called transverse flow rate gradient). The levels of this gradient determine the orientation of structural elements along the fibre axis, and thus also the strength properties of the fibres. The macromolecular structure of alginate fibres is rather rigid, which means that the characteristics of the final product largely depend on the as-spun draw ratio and the stresses occurring during solidification, which have a fundamental effect on fibre structure and its transformations during deformation processes in consecutive stages to type of fibre formation [17-19]. The objective of the present work was to determine the influence of the concentration of sodium alginate on the rheological parameters of spinning solutions. At the same time, we determined the most advantageous concentrations of spinning liquids for the process of wet spinning from solution.

\section{Experimental}

\subsection{Materials and methods}

In the presented study, we used sodium alginate from SigmaAldrich with an intrinsic viscosity of $1.132 \mathrm{dL} / \mathrm{g}$ (which is viscosimetrically equivalent to an average molecular weight of approximately $36.000 \mathrm{~g} / \mathrm{mol}$ ) and also Protanal LF 10/60 LS sodium alginate from FMC Biopolymer with an intrinsic viscosity of $2.609 \mathrm{dL} / \mathrm{g}$ (which is viscosimetrically equivalent to an average molecular weight of approximately $89.000 \mathrm{~g} /$ mol). For rheological studies, we used aqueous solutions of sodium alginate at a concentration of $9 \%$ to $14 \%$ for the first type of polymer and $5 \%$ to $8.4 \%$ for the second type of polymer. The rheological properties of spinning solutions were measured using a Rheolab QC rotational rheometer from Anton Paar. Measurements were conducted at shear rates from 0 to $160 \mathrm{~s}^{-1}$ at $20^{\circ} \mathrm{C}$ using a CC17 cylinder. Specific tensile strength (tenacity) was tested using an Instron 5944 universal testing machine. The fibers were spun from solution by the wet method. An aqueous solution of $\mathrm{CaCl}_{2}$ at a concentration of $3 \%$ and a temperature of $15^{\circ} \mathrm{C}$ was used as a solidification bath. The first stage of drawing was conducted in a plasticising bath (an aqueous solution of $\mathrm{CaCl}_{2}$ at a concentration of $3 \%$ and a temperature of $70^{\circ} \mathrm{C}$ ). The second stage of drawing was conducted in overheated water steam at $120^{\circ} \mathrm{C}$.

\section{Results and discussion}

In the case of wet spinning from solution, the polymer solution concentration must be such that apparent dynamic viscosity is appropriate for stable solution processing into fibres. While low concentrations of spinning solutions may compromise 
the continuity of the spinning solution stream, excessive concentrations increase apparent dynamic viscosity, which may disrupt the formation process. The rheological parameters of the studied spinning solutions have a significant effect both on flow rate distribution during spinning solution flow in spinneret channels and on the longitudinal flow rate gradient along the fibre formation pathway. The value of the longitudinal flow rate gradient considerably affects the orientation of structural fibre elements. The research results of sodium alginate solutions (Figures 1 and 2) show that they are shear-thinning nonNewtonian fluids without a flow limit. For all solutions, shear stress increases less than proportionally with the shear rate. Apparent dynamic viscosity decreases with increasing shear rate, which is typical of polymer solutions (Figures 1 and 2).
Table 1. Rheological parameters of sodium alginate (Sigma-Aldrich) solutions of different concentrations

\begin{tabular}{|c|c|c|}
\hline \multirow{2}{*}{$\begin{array}{c}\text { Polymer } \\
\text { concentration } \\
{[\%]}\end{array}$} & $\mathbf{n}$ & $\mathbf{k}$ \\
\cline { 2 - 3 } & 0.988 & 3.29 \\
\hline 9 & 0.816 & 9.09 \\
\hline 10 & 0.776 & 16.11 \\
\hline 11 & 0.717 & 21.85 \\
\hline 12 & 0.712 & 36.47 \\
\hline 13 & 0.666 & 60.56 \\
\hline 14 &
\end{tabular}

Tables 1 and 2 present the rheological parameters obtained for the studied polymer solutions.

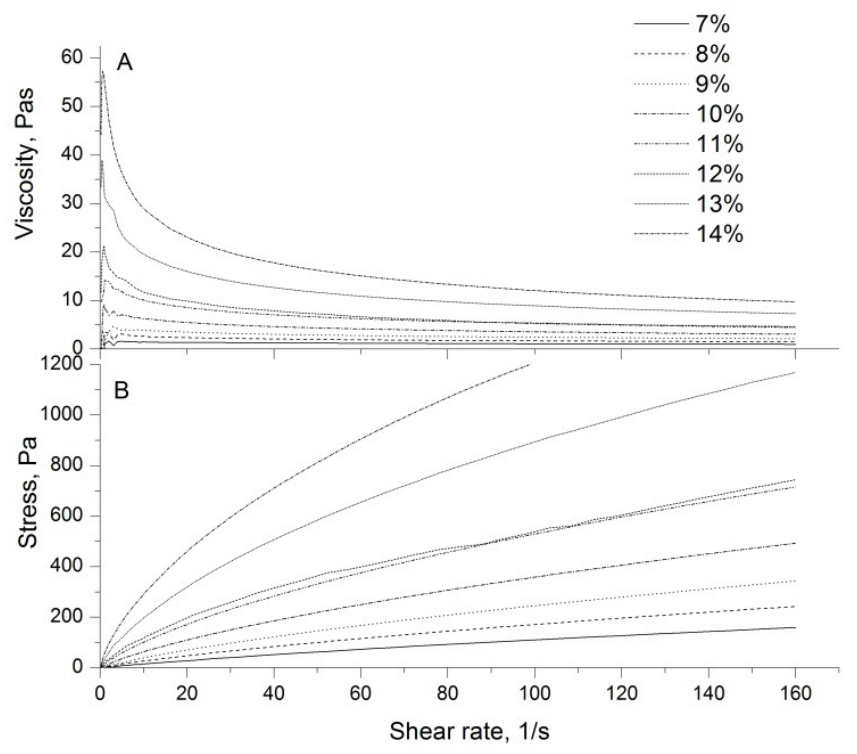

Figure 1. A)Relationship between apparent dynamic viscosity and the shear rate for sodium alginate (Sigma-Aldrich) solutions of different concentrations ; B) Flow curves for sodium alginate (Sigma-Aldrich) solutions of different concentrations

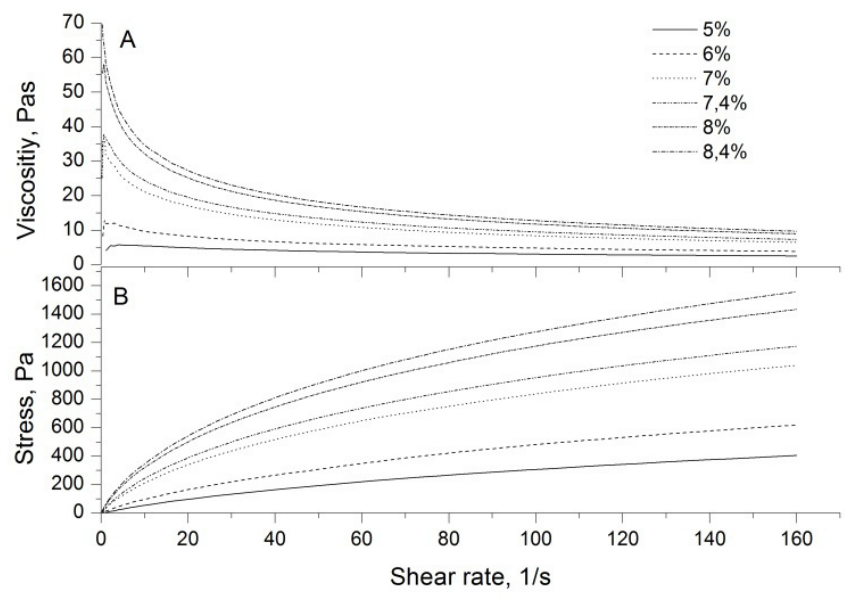

Figure 2. A)Relationship between apparent dynamic viscosity and the shear rate for sodium alginate (Protanal LF 10/60 LS) solutions of different concentrations ; B) Flow curves for sodium alginate (Protanal LF 10/60 LS) solutions of different concentrations 
Table 2. Rheological parameters of sodium alginate (Protanal LF 10/60 LS) solutions of different concentrations

\begin{tabular}{|c|c|c|}
\hline \multirow{2}{*}{$\begin{array}{c}\text { Polymer } \\
\text { concentration } \\
{[\%]}\end{array}$} & \multicolumn{2}{|c|}{ Rheological parameters } \\
\cline { 2 - 3 } & $\mathbf{n}$ & $\mathbf{k}$ \\
\hline 5 & 0.959 & 4.12 \\
\hline 6 & 0.797 & 12.89 \\
\hline 7 & 0.704 & 38.49 \\
\hline 7.4 & 0.701 & 44.39 \\
\hline 8 & 0.666 & 63.75 \\
\hline 8.4 & 0.664 & 69.69 \\
\hline
\end{tabular}

The rheological parameter $\mathrm{k}$, which is a measure of solution consistency, increases with increasing polymer concentration in the solution, which is typical of solutions of high molecular weight compounds. Importantly, in the case of 7-8\% concentrations of the Protanal LF10/60LS polymer, apparent dynamic viscosity values are in the range of 40-60 Pas, while in the case of the Sigma-Aldrich polymer, such levels of the rheological parameter are obtained at concentrations of 13$14 \%$.

These differences follow from the characteristics of the polymers applied. The molar mass of the Sigma-Aldrich polymer is lower than that of the Protanal LF10/60LS polymer (Mv $=36.000 \mathrm{~g} /$ $\mathrm{mol}$ and $\mathrm{Mv}=89.000 \mathrm{~g} / \mathrm{mol}$, respectively).
The obtained values of the rheological parameter $\mathrm{n}$ show that higher concentrations of both polymers in the solution increase the non-Newtonian behaviour of the solution. In the case of the Sigma-Aldrich polymer, the value of the $n$ parameter decreased from 0.988 to 0.666 with the solution concentration increasing from $9 \%$ to $14 \%$, and in the case of Protanal LF10/60LS it decreased from 0.959 to 0.664 with the concentration increasing from $5 \%$ to $8.4 \%$.

For both studied polymers, we determined spinning solution concentrations for which apparent dynamic viscosity fell within the range appropriate for wet spinning from solution. These concentrations were $12 \%$ and $13 \%$ for the Sigma-Aldrich polymer and $7.4 \%$ and $8 \%$ for the Protanal LF10/60LS polymer.

Analysis of the strength properties of the obtained fibres revealed that at similar total draw ratios the Sigma-Aldrich polymer resulted in a slightly higher tenacity at a polymer concentration of $12 \%$ (Table 3 ). At the same time, the highest tenacity $(15.54 \mathrm{cN} /$ tex $)$ was found at an as-spun draw ratio of $+100 \%$, which is probably due to a more advantageous orientation of macromolecules in the coagulation bath. For the Protanal LF10/60LS polymer, the highest tenacity $(23.37 \mathrm{cN} /$ tex) was obtained for the polymer concentration of $7.4 \%$ at an as-spun draw ratio of +50 (Table 4 ).

The considerable differences in tenacity between fibers made from the two polymers are probably attributable to the fact that the polymers significantly differ in terms of molar mass. Protanal LF10/60LS, with a higher molar mass, exhibited higher tensile strength as well as slightly higher total draw ratios.

Table 3. Fibre formation conditions and properties of alginate fibres (Sigma-Aldrich)

\begin{tabular}{|c|c|c|c|c|c|}
\hline $\begin{array}{c}\text { Sample } \\
\text { symbol }\end{array}$ & $\begin{array}{c}\text { Polymer } \\
\text { concentration [\%] }\end{array}$ & $\begin{array}{c}\text { As-spun drew } \\
\text { ratio [\%] }\end{array}$ & $\begin{array}{c}\text { Total drew ratio } \\
{[\%]}\end{array}$ & $\begin{array}{c}\text { Tenacity [cN/tex] } \\
\text { Elongation at } \\
\text { break [\%] }\end{array}$ \\
\hline S1 & 12 & 50 & 70 & 14.66 & 5.37 \\
\hline S2 & 12 & 100 & 70 & 15.54 & 4.89 \\
\hline S3 & 13 & 50 & 74 & 14.39 & 4.2 \\
\hline S4 & 13 & 100 & 70 & 14.59 & 5.36 \\
\hline
\end{tabular}

Fibre solidification $-3 \% \mathrm{CaCl}_{2}, 15^{\circ} \mathrm{C}$; Draw ratio in coagulation bath $-3 \% \mathrm{CaCl}_{2}, 70^{\circ} \mathrm{C}$; Draw ratio in water vapor $-120^{\circ} \mathrm{C}$; Draw ratio in plasticising bath $-70 \%$.

Table 4. Fibre formation conditions and properties of alginate fibres (Protanal LF 10/60 LS)

\begin{tabular}{|c|c|c|c|c|c|}
\hline $\begin{array}{c}\text { Sample } \\
\text { symbol }\end{array}$ & $\begin{array}{c}\text { Polymer } \\
\text { concentration [\%] }\end{array}$ & $\begin{array}{c}\text { As-spun drew } \\
\text { ratio [\%] }\end{array}$ & $\begin{array}{c}\text { Total drew ratio } \\
\text { [\%] }\end{array}$ & $\begin{array}{c}\text { Tenacity [cN/tex] } \\
\text { Elongation at } \\
\text { break [\%] }\end{array}$ \\
\hline P1 & 7.4 & 50 & 83 & 23.37 & 6.95 \\
\hline P2 & 7.4 & 100 & 85 & 21.13 & 6.72 \\
\hline P3 & 8 & 50 & 80 & 20.27 & 9.028 \\
\hline P4 & 8 & 100 & 77.5 & 20.15 & 7.05 \\
\hline
\end{tabular}

Fibre solidification $-3 \% \mathrm{CaCl}_{2}, 15^{\circ} \mathrm{C}$; Draw ratio in coagulation bath $-3 \% \mathrm{CaCl}_{2}, 70^{\circ} \mathrm{C}$; Draw ratio in water vapor $-120^{\circ} \mathrm{C}$; Draw ratio in plasticising bath $-70 \%$. 


\section{Conclusions}

Rheological studies of aqueous spinning solutions of sodium alginate led to the determination of appropriate alginate concentrations for wet spinning. Spinning tests revealed very good spinability and solidification properties of both polymers.

In the spinning tests, fibres produced from the Sigma-Aldrich polymer were found to have a tenacity of approximately 14-16 cN/tex, while those made from Protanal LF10/60LS exhibited a tenacity of 20-24 cN/tex.

The considerable tenacity differences between the fibres made from the two polymers are attributable to the fact that the polymers differ significantly in terms of their molar mass.

\section{ACKNOWLEDGEMENT}

Project was funded by the National Science Centre awarded on the basis of the decision number DEC-2012/05/B/ST8/00249.

\section{References}

[1] Speakman J. B., Chamberlain N. H., The Production of Rayon from Alginic Acid. Journal of the Society of Dyers and Colourists Volume 60, Issue 10, pages 264-272, (October 1944).

[2] Barikosky M., Dressing product with a calcium alginate matrix and method of production of the same, US Patent 5,981,821 (1999).

[3] Fenton J.C., Keys A.F., Mahoney P.M.J., Alginate fabric, its use in wound dressing and surgical hemostats and a process for its manufacture, US Patent 5,714,955 (1998).

[4] Griffiths B., Mahoney P.M.J., Sustained release alginate fibre and process for the preparation thereof, US Patent 5,690,955 (1997).

[5] Mahoney P.M.J., Walker K., Alginate fibres, manufacture and use, US Patent 5,874,100 (1999).

[6] Hosler J.A., Wound dressing and manufacture thereof, US Patent 6,153,214 (2000).
[7] Qin Y., Gilding D.K., Fibres of cospun alginates, US Patent 6,080,420 (2000).

[8] Langer R., Vacanti J.P., Tissue engineering, Science 260, (1993), 920-926.

[9] Olszewska- Słonina D.M., Drewa T.A., Hodowla komórek, inżynieria tkankowa i medycyna regeneracyjna. Część I, Wiadomości Lekarskie LIX, (2006), 585-589.

[10] Qurrat-ul-Ain, Sharma S., Khuller G.K., Garg S.K., Alginate-based oral drug delivery system for tuberculosis: pharmacokinetics and therapeutic effects, J. Antimicro. Chemother. 51, (2003), 931-938.

[11] Ciofani G., Raffa V., Pizzorusso T., Menciassi A., Dario $P$., Characterization of an alginate-based drug delivery system for neurological applications, Med. Eng.\&Phys. 30, (2008), 848-855.

[12] Ciofani G., Raffa V., Menciassi A., Dario P., Alginate and chitosan particles as drug delivery system for cell therapy, Biomed. Microdevices 10, (2007), 131-140.

[13] Tønnesen H.H., Karlsen J., Alginate in Drug Delivery Systems, Drug Dev. Ind. Pharm. 28, (2002), 621-630.

[14] Pielesz A., Algi $i$ alginiany - leczenie, zdrowie $i$ uroda. Wydawnictwo internetowe e-bookowo ISBN 978-8361184-97-3. (2010).

[15] Painter T.J., Smidsrød O., Haug A., A computer study of the changes in composition-distribution occurring during random depolymerisation of binary linear heteropolysaccharide, Acta Chem. Scand. 22, (1968), 1637-1648.

[16] Smidsrød O, Whittington S. G., Monte Carlo investigation of chemical inhomogeneity in copolymers, Macromolecules 2, (1969), 42-44.

[17] Mikołajczyk, T., Wołowska-Czapnik, D., Boguń, M.; Precursor alginate fibres containing nano-particles of $\mathrm{SiO}_{2}$; Fibres and Textiles in Eastern Europe; Volume 12, Issue 3, July 2004, Pages 19-23.

[18] Stodolak, E., Paluszkiewicz, C., Bogun, M., Blazewicz, M.; Nanocomposite fibres for medical applications; Journal of Molecular Structure; Volume 924-926, Issue C, 30 April 2009, Pages 208-213.

[19]Boguń, M.; Rheological properties of sodium alginate spinning solutions with ceramic nanoadditives; Fibres and Textiles in Eastern Europe; Volume 76, Issue 5, 2009, Pages 17-22. 